\title{
Mesenchymal stem cells with downregulated Hippo signaling attenuate lung injury in mice with lipopolysaccharide-induced acute respiratory distress syndrome
}

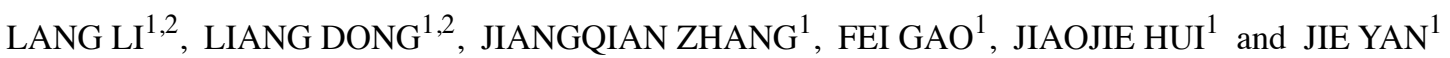 \\ Departments of ${ }^{1}$ Critical Care Medicine and ${ }^{2}$ Translational Medicine, Wuxi People's Hospital, \\ Nanjing Medical University, Wuxi, Jiangsu 214023, P.R. China
}

Received May 4, 2018; Accepted December 27, 2018

DOI: $10.3892 / \mathrm{ijmm} .2018 .4047$

\begin{abstract}
Mesenchymal stem cell (MSC)-mediated repair of injured alveolar epithelial cells is a promising potential cure for acute respiratory distress syndrome (ARDS); however, the repairing effect of MSCs is limited by poor homing and differentiation. Our previous study revealed that the inhibition of the Hippo signaling pathway promotes the proliferation, migration and differentiation of MSCs in vitro, leading to the hypothesis that MSCs with downregulated Hippo signaling could further ameliorate lipopolysaccharide (LPS)-induced ARDS in vivo. In the current study, mouse bone marrow-derived MSCs (mMSCs) with downregulated Hippo signaling were constructed by shRNA-mediated knockdown of large tumor suppressor kinase 1 (Lats1) and were intratracheally administered to LPS-induced mouse models of ARDS. The inhibition of Hippo signaling increased the retention of mMSC in ARDS lung tissue and their differentiation toward alveolar type II epithelial cells. Furthermore, mMSCs with downregulated Hippo signaling led to a decreased lung wet weight/body weight ratio, decreased total protein and albumin concentrations in bronchoalveolar lavage fluid, decreased levels of proinflammatory factors and increased levels of anti-inflammatory factors. Finally, mMSCs with downregulated Hippo signaling improved pathological changes and decreased pulmonary fibrosis in lungs of mice with ARDS. These results suggest that the inhibition of the Hippo signaling pathway in mouse mMSCs by knockdown of Lats1 could further improve the protective effects of mMSCs against epithelial damage and the therapeutic potential of mMSCs on mice with ARDS.
\end{abstract}

Correspondence to: Dr Liang Dong, Department of Critical Care Medicine, Wuxi People's Hospital, Nanjing Medical University, 299 Qingyang Road, Wuxi, Jiangsu 214023, P.R. China

E-mail: dongliang@njmu.edu.cn

Key words: mesenchymal stem cell, Hippo signaling, large tumor suppressor kinase 1, alveolar type II epithelial cell, acute respiratory distress syndrome

\section{Introduction}

Acute respiratory distress syndrome (ARDS) is a refractory respiratory failure that represents one of the most clinically severe acute disorders (1). ARDS is pathophysiologically characterized by alveolar epithelial cell damage. Currently, the treatment efficacy of ARDS by mechanical ventilation and medication is poor, and the mortality rate of ARDS remains high (2). Stem cell-mediated repair of injured alveolar epithelial cells is promising for improving the outcomes of ARDS (3). Due to their high self-renewal and differentiation potential, mesenchymal stem cells (MSCs) are ideal for cell-based tissue repair strategies (4). Animal studies revealed that exogenous MSCs can target and repair sites of experimental ARDS-associated alveolar epithelial injury $(5,6)$. However, the proportion of MSCs with effective restorative properties that home to ARDS lung tissue is relatively low due to low retention time and impaired migration capacity $(7,8)$. Therefore, determining the mechanisms that promote MSC differentiation, migration, proliferation, and resistance to injury may improve the outcomes of ARDS $(9,10)$.

Our laboratory has previously demonstrated that the inhibition of the Hippo signaling pathway in vitro may enhance the differentiation of MSCs into alveolar type II epithelial (ATII) cells, stimulate MSC proliferation and migration toward ARDS lung tissue, and strengthen MSC resistance to oxidative stress (11). This approach may provide a novel method to optimize cell-based ARDS treatments. However, experimental microenvironmental conditions and regulatory mechanisms exhibit increased complexity in vivo, and there remains insufficient evidence of whether the modulation of the Hippo signaling may enhance the protective role of MSCs in the lungs of animal models of ARDS.

In a previous study, we successfully constructed a C57BL/6 mouse bone marrow-derived mesenchymal stem cell (mMSC) line with Lats1 gene (NCBI Reference Sequence: NM_010690; www.ncbi.nlm.nih.gov/genbank) knockdown and demonstrated that the downregulation of the Hippo signaling promoted differentiation, proliferation, and migration of these mMSCs in vitro (11). Therefore, the current study aimed to confirm the effect of manipulating the Hippo signaling on MSC-mediated repair of ARDS lung injury in vivo by trans- 
planting mMSCs with shRNA-mediated knockdown of Lats1 into the airways of mouse models of ARDS.

\section{Materials and methods}

Materials and reagents. Lipopolysaccharide (LPS; isolated from Escherichia coli 0111:B4) and dimethylsulfoxide (DMSO) were purchased from Sigma-Aldrich (Merck KGaA, Darmstadt, Germany). C57BL/6 mMSCs were obtained from Cyagen Biosciences, Inc. (Santa Clara, CA, USA). Fetal bovine serum (FBS) and Dulbecco's modified Eagle's medium/nutrient mixture F-12 (DMEM/F12) were obtained from Thermo Fisher Scientific, Inc. (Waltham, MA, USA). Trypsin was purchased from Gibco (Thermo Fisher Scientific, Inc.). The bicinchoninic acid (BCA) protein quantitation reagent kit, nuclear and cytoplasmic protein extraction kits (cat. no. P0027), and horseradish peroxidase-conjugated goat anti-mouse immunoglobulin G (IgG; cat. no. A0216) were purchased from Beyotime Institute of Biotechnology (Nanjing, China). CellVue NIR815 dye was purchased from eBioscience (Thermo Fisher Scientific, Inc.). Mouse anti-green fluorescent protein (GFP) antibody (cat. no. ab1218) was purchased from Abcam (Cambridge, MA, USA). Rabbit antibodies against Lats1, surfactant protein C (SPC), occludin, $\beta$-actin and GAPDH (cat. nos. sc-398560, sc-518029, sc-133256, sc-47778 and sc-32233, respectively) were purchased from Santa Cruz Biotechnology, Inc. (Dallas, TX, USA). Mouse interleukin (IL)-1 $\beta$, IL-6, IL-4 and IL-10 ELISA detection kits (cat. nos. 559603, 550950, 555232 and 555252, respectively) were purchased from BD Biosciences (San Jose, CA, USA). Mouse total protein (TP) and albumin (ALB) ELISA detection kits (cat. nos. ml001923 and ml022503, respectively) were purchased from Shanghai Enzyme-Linked Biotechnology Co., Ltd. (Shanghai, China).

Transfection and culture of $m M S C s$. Lentiviral transfection of C57BL/6 mMSCs was performed as previously reported by our laboratory (11). The protein and mRNA expression levels of Lats1 were measured by western blotting and reverse transcription-quantitative polymerase chain reaction (RT-qPCR) to confirm stable and effective transfection of mMSCs by lentiviral vector. Following successful transfection, mMSCs were grown and passaged in DMEM/F12 culture medium containing $10 \%$ FBS and $1 \%$ streptomycin and penicillin at $37^{\circ} \mathrm{C}$ in an atmosphere with $5 \% \mathrm{CO}_{2}$. Subsequent experiments were performed on passage 6 or 7 cells.

Experimental animals and the induction of $A R D S$. A total of 60 male SPF-grade C57BL/6 mice (age, 6-8 weeks; weight, 20-25 g), were obtained from the Research Animal Center of the Academy of Military Medical Sciences (Beijing, China). The experimental protocols were approved by the Institutional Animal Care and Use Committee at Nanjing Medical University (Wuxi, China), and all animal use met the requirements of the Guide for the Care and Use of Laboratory Animals (12). The mice were maintained under specific pathogen-free conditions with a 12 -h light/dark cycle (temperature, $18-23^{\circ} \mathrm{C}$; humidity, 40-60\%) and fed standard rodent chow and water ad libitum, and adapted to laboratory conditions for at least 3 days before experimentation. After the mice were anesthetized by an intra- peritoneal injection of $50 \mathrm{mg} / \mathrm{kg}$ pentobarbital, ARDS was induced by intratracheal administration of $50 \mu 12 \mathrm{mg} / \mathrm{ml}$ LPS using a micropipette. The mice recovered in an oxygenated cage until fully awake.

Experimental animal groups. C57BL/6 mice were randomly divided into four groups of equal size ( $\mathrm{n}=15 \mathrm{mice} / \mathrm{group}$ ) as follows: Normal mice (control), mice with ARDS (ARDS), mice with ARDS treated with mMSCs transfected with empty lentivirus [ARDS + MSC-short hairpin RNA (sh)control], and mice with ARDS treated with mMSCs transfected with Lats1-interfering lentivirus (ARDS + MSC-shLats1). Instead of ARDS induction, the mice in the control group were initially injected intratracheally with $50 \mu \mathrm{l}$ of saline and after $4 \mathrm{~h}, 30 \mu \mathrm{l}$ of PBS. ARDS was modeled by the intratracheal injection of $50 \mu \mathrm{l}$ of LPS solution, and ARDS mice received an additional $30 \mu \mathrm{l}$ injection of PBS $4 \mathrm{~h}$ after exposure to LPS. In the ARDS + MSC-shcontrol group, $30 \mu \mathrm{l}$ PBS containing mMSCs transfected with empty lentivirus ( $5 \times 10^{4}$ cells) was injected into the airway $4 \mathrm{~h}$ after exposure to LPS. In the ARDS + MSC-shLats1 group, $30 \mu$ l PBS containing mMSCs transfected with Lats1-interfering lentivirus $\left(5 \times 10^{4}\right.$ cells) was injected into the airway $4 \mathrm{~h}$ after exposure to LPS. Mice were sacrificed 3, 7, and 14 days after the establishment of LPS-induced ARDS, and intact lung tissue was harvested for subsequent experiments.

Hematoxylin and eosin staining of lung tissue and lung injury scoring. Lung tissue from the right upper lobe was fixed in $10 \%$ neutral formaldehyde at $4^{\circ} \mathrm{C}$ for $24 \mathrm{~h}$ and embedded in formalin. After sequential staining with hematoxylin for $5 \mathrm{~min}$ and eosin for $2 \mathrm{~min}$ at $25^{\circ} \mathrm{C}$ and consecutive transverse slicing into $5-\mu \mathrm{m}$-thick sections, 10 high magnification (x400; light microscopy) visual fields were randomly selected for semiquantitative evaluation of lung injury based on the method reported by Smith et al (13), and the average value was determined.

Modified Masson's staining of lung tissue and pulmonary fibrosis scoring. Lung tissue from the right lower lobe was fixed in $10 \%$ neutral formaldehyde at $4^{\circ} \mathrm{C}$ for $24 \mathrm{~h}$ and embedded in formalin. After sequential staining with Weigert's Iron haematoxylin for $10 \mathrm{~min}$, Biebrish scarlet-acid fuchsin for $5 \mathrm{~min}$ and aniline blue for $5 \mathrm{~min}$ (all at $25^{\circ} \mathrm{C}$ ) and consecutive transverse slicing into $4-\mu \mathrm{m}$-thinck sections, $10 \mathrm{high}$ magnification (x400; light microscopy) visual fields were randomly selected for semiquantitative scoring of pulmonary fibrosis based on the scoring method reported by Ashcroft et al (14), and the average value was determined.

mMSC labeling and tracking. The cultured MSC-shcontrol and MSC-shLats1 cells were harvested and labeled with CellVue NIR815 dye according to the manufacturer's protocol. Labeled cells $\left(5 \times 10^{5}\right.$ cells) were directly injected into the airways of the ARDS + MSC-shcontrol and ARDS + MSC-shLats1 groups under isoflurane anesthesia. Ex vivo lungs from three mice/group were imaged using a Maestro II small animal in vivo imaging system (PerkinElmer, Inc., Walham, MA, USA) at 3, 7, and 14 days after cell injection to observe mMSC retention in the lungs. A filter set with $786 \mathrm{~nm}$ excitation and 
$814 \mathrm{~nm}$ emission was used to detect the fluorescence signal, and the exposure time was 4,000 msec. The autofluorescence spectra were then unmixed based on their spectral patterns using Maestro ${ }^{\mathrm{TM}} 2.2$ software (PerkinElmer, Inc.). The fluorescence intensity of the lungs was measured by placing fixed size boxes on the organ of interest to observe the changes in counts in the box of that organ over time, and the average signals were normalized by the exposure time and the area of the ROI (scaled counts/sec).

Immunofluorescence staining of lung tissue. Left lung tissue was embedded in $10 \%$ optimal cutting temperature medium (Thermo Fisher Scientific, Inc.), sectioned at $-20^{\circ} \mathrm{C}$, and fixed in $2 \%$ acetone at $4^{\circ} \mathrm{C}$ for $15 \mathrm{~min}$. After air-drying at $25^{\circ} \mathrm{C}$, the samples were hydrated, permeabilized with $0.3 \%$ Triton $\mathrm{X}-100$ (Thermo Fisher Scientific, Inc.) at $25^{\circ} \mathrm{C}$ for $30 \mathrm{~min}$ and blocked with $3 \%$ bovine serum ALB (Thermo Fisher Scientific, Inc.) at $25^{\circ} \mathrm{C}$ for $5 \mathrm{~min}$. Primary antibodies against GFP (1:100) and/or SPC $(1: 100)$ were added, incubated at $4^{\circ} \mathrm{C}$ overnight, and washed with PBS. A fluorescent fluorescein isothiocyanate/tetramethylrhodamine-labeled secondary antibody (cat. no. ab228549; 1:1,000; Abcam) was added, incubated at $25^{\circ} \mathrm{C}$ for $1 \mathrm{~h}$, and washed with PBS. Subsequently, 4',6-diamidino-2-phenylindole was added at $25^{\circ} \mathrm{C}$ for $10 \mathrm{~min}$, and the slide was mounted and sealed. Five randomly selected high-power fields for each slide were observed and imaged at high magnification ( $\mathrm{x} 400)$ using a fluorescence microscope (Olympus Corporation, Tokyo, Japan). The count of GFP-positive cells represented the retention of transplanted mMSCs in the lung, while the ratio of the count of double-positive cells to the count of GFP-positive cells represented the differentiation of transplanted mMSCs into ATII cells in the lung (15).

Western blotting. Nuclear protein and cytoplasmic protein extraction kits were used to isolate the TP and cytoplasmic protein. A BCA assay was used to measure the protein concentration. Proteins were denatured and added to the wells in aliquots of $25 \mu \mathrm{l} /$ well. After SDS-PAGE (10\% gel), the proteins were transferred to a polyvinylidene fluoride membrane, blocked with Tris-buffered saline with Tween-20 (TBST) containing 5\% skim milk powder at $25^{\circ} \mathrm{C}$ for $1 \mathrm{~h}$, and incubated at $4^{\circ} \mathrm{C}$ overnight with primary antibodies against Lats1, SPC and occludin (all at 1:400 dilution). $\beta$-actin (1:400) or GAPDH (1:400) was used as an internal reference protein. Lats1 and GAPDH were used with total protein, and SPC, occludin and $\beta$-actin were used with cytoplasmic protein. The membrane was washed three times with TBST and incubated with the aforementioned horseradish peroxidase-conjugated secondary antibody (cat. no. A0216; 1:1,000) at $25^{\circ} \mathrm{C}$ for $1 \mathrm{~h}$. The membrane was washed four times with TBST, developed with the Pierce ${ }^{\mathrm{TM}}$ Enhanced Chemiluminescence reagent (Pierce; Thermo Fisher Scientific, Inc.), and placed on an X-ray film for imaging. Quantity One 4.6.7 software (Bio-Rad Laboratories, Inc., Hercules, CA, USA) was used for quantitative analysis of the grayscale values of the bands.

RT-qPCR detection of Lats1 mRNA expression. Total RNA was extracted from mMSCs in culture plates using the TRIzol reagent (Thermo Fisher Scientific, Inc.). Total RNA $(2 \mu \mathrm{g})$ was subsequently reverse transcribed to yield single-stranded
cDNAs using the High-Capacity cDNA Reverse Transcription kit (Thermo Fisher Scientific, Inc.). The reverse transcription is performed accordingly the following protocol: $25^{\circ} \mathrm{C}$ for $10 \mathrm{~min}, 37^{\circ} \mathrm{C}$ for $120 \mathrm{~min}$ and $85^{\circ} \mathrm{C}$ for $5 \mathrm{~min}$. An ABI Prism 7500 quantitative PCR instrument (Applied Biosystems; Thermo Fisher Scientific, Inc.) was used for product amplification. Each sample was analyzed in triplicate with the following thermocycling conditions: 40 cycles, including a denaturation step at $95^{\circ} \mathrm{C}$ for $15 \mathrm{sec}$, an annealing step at $56^{\circ} \mathrm{C}$ for $20 \mathrm{sec}$ and an extension step at $72^{\circ} \mathrm{C}$ for $40 \mathrm{sec}$. SYBR-Green I (Thermo Fisher Scientific, Inc.) was selected as a fluorophore dye. The $2^{-\Delta \Delta \mathrm{Cq}}$ method was used to calculate the relative expression levels of Mrna (16), and GAPDH was used as the internal reference gene. The PCR primers used were as follows: Lats1 forward, 5'-CCACCCTACCCAAAACATCTG-3' and reverse, 5'-CGCTGCTGATGAGATTTGAGTAC-3'; and GAPDH forward, 5'-TATGTCGTGGAGTCTACTGGT-3' and reverse, 5'-GAGTTGTCATATTTCTCGTGG-3'.

Cytokine and protein detection in bronchoalveolar lavage fluid $(B A L F)$. Following aesthesia with pentobarbital, the anterior trachea was exposed and intubated. BALF was collected by flushing $1 \mathrm{ml}$ ice-cold PBS back and forth three times through a tracheal cannula and subsequent centrifugation at $1,000 \times \mathrm{g}$ at $4^{\circ} \mathrm{C}$ for $10 \mathrm{~min}$, the supernatant was stored at $-80^{\circ} \mathrm{C}$. To evaluate the inflammatory responses in lungs and alveolar epithelial permeability, IL-1 $\beta,-6,-4$ and -10 concentrations, TP, and ALB content were measured according to the protocols provided with the aforementioned ELISA reagent kits.

Detection of pulmonary edema. Whole lung tissue was collected, and residual bronchioles and connective tissue were carefully cut away. Absorbent paper was used to completely absorb water from the lung surface and to remove blood contamination. The lungs were weighed, and the lung wet weight/body weight ratio (LWW/BW), which reflects pulmonary edema and the degree of injury, was determined (17).

Statistical analysis. The SPSS statistical software package (version 20.0; IBM Corp., Armonk, NY, USA) was used for statistical analysis. Quantitative data are presented as the mean \pm standard deviation and comparison among multiple groups were performed using one-way analysis of variance followed by Bonferroni's post hoc test. $\mathrm{P}<0.05$ was considered to indicate a statistically significant difference.

\section{Results}

Successful Latsl knockdown in mMSCs using a lentiviral vector. Lats1 protein (Fig. 1A) and mRNA (Fig. 1B; $\mathrm{P}<0.05$ ) expression levels in MSC-shLats1 were lower compared with the MSC and MSC-shcontrol groups, however, there was no significant difference in Lats1 protein and mRNA expression level between MSC and MSC-shcontrol. These results suggested that the lentiviral vector-mediated Lats1 knockdown in mMSCs was effective.

Lats1 knockdown increases mMSCs retention in ARDS lung tissue. Analysis of color-coded fluorescence images indicated 

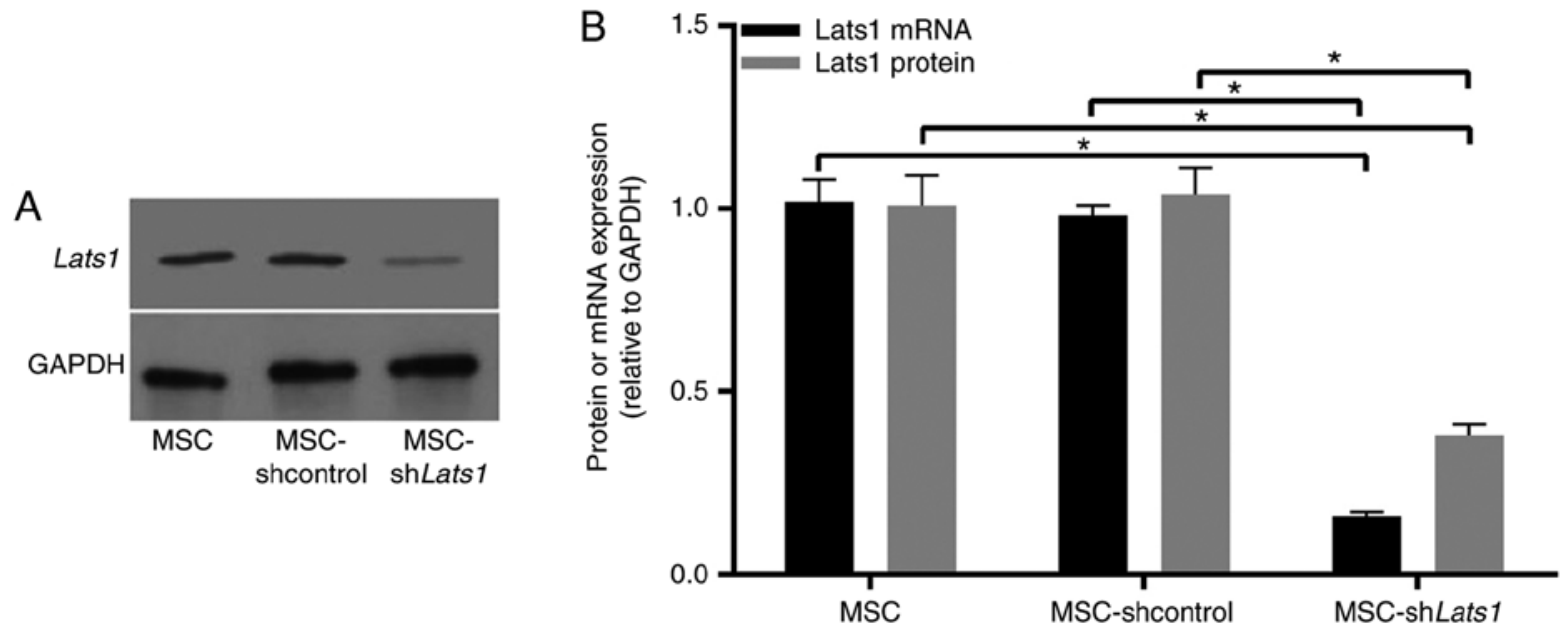

Figure 1. Transgene expression levels of Lats1 in mMSCs after lentiviral vector transduction. Lats1 (A) protein and (B) mRNA expression level in mMSCs following lentiviral vector transduction were measured by western blotting and reverse transcription-quantitative polymerase chain reaction, respectively. GAPDH was used as an internal reference $(n=3)$. ${ }^{*} \mathrm{P}<0.05$. mMSC, bone marrow-derived mesenchymal stem cell; Lats1, large tumor suppressor kinase 1.

that average signals of ex vivo lungs from mice exposed to shLats1 mMSCs labeled with NIR815 were significantly greater compared with those in the lungs from ARDS + MSC-shcontrol animals 3, 7 and 14 days after LPS exposure (all $\mathrm{P}<0.05$ ); however, the signal intensities decreased progressively over time (Fig. 2A). Fluorescence microscopy revealed that the number of GFP-positive cells in the lung tissue of the ARDS + MSC-shLats1 group was significantly greater compared with that in the ARDS + MSC-shcontrol group 3, 7 and 14 days after LPS exposure (all $\mathrm{P}<0.05$ ); however, the number of GFP-positive cells decreased progressively over time (Fig. 2B). These results indicate that Lats1 knockdown increased the retention of mMSCs in ARDS lung tissue.

Lats1 knockdown increases mMSCs differentiation into ATII cells. To evaluate the differentiation of mMSCs into ATII cells, the expression of SPC was detected by western blotting and immunofluorescence staining 14 days after mMSC administration. Western blot analysis revealed that the protein expression level of the ATII cell-specific marker SPC was significantly greater in the ARDS + MSC-shcontrol group compared with the ARDS group $(\mathrm{P}<0.05)$. In the ARDS + MSC-shLats1 group, the SPC protein expression level was greater compared with the ARDS + MSC-shcontrol group $(\mathrm{P}<0.05$; Fig. 3A) Cells positive for GFP (green) or SPC protein expression (red) under fluorescence microscopy were mMSCs and ATII cells, respectively. Double-positive cells appeared yellow and indicated mMSCs that differentiated into ATII cells. There was no difference in the number of mMSCs and ATII cells in the lung tissue of mice from the ARDS + MSC-shLats1 and ARDS + MSC-shcontrol groups (data not shown); however, the proportion of mMSCs that differentiated into ATII cells was significantly greater in the ARDS + MSC-shLats1 group compared with the ARDS + MSC-shcontrol group ( $\mathrm{P}<0.05$; Fig. 3B). These results suggest that Lats1 knockdown promoted mMSC differentiation into ATII cells.

mMSCs with downregulated Hippo signaling improve pulmonary edema and permeability of lung epithelium in ARDS lung tissue. The LWW/BW, which reflects the degree of pulmonary edema (17), in the ARDS + MSC-shcontrol group was significantly lower compared with the ARDS group 3 and 14 days after LPS exposure (both $\mathrm{P}<0.05$ ). Furthermore, the LWW/BW in the ARDS + MSC-shLats1 group was lower compared with the ARDS + MSC-shcontrol group 3 and 14 days after LPS exposure (both $\mathrm{P}<0.05$; Fig. $4 \mathrm{~A}$ and $\mathrm{B}$ ). TP and ALB concentrations in the BALF reflect the permeability of the lung epithelium (18). BALF TP and ALB concentrations in the ARDS + MSC-shcontrol group were significantly lower compared with the ARDS group 3 and 14 days after LPS exposure (all $\mathrm{P}<0.05)$. Furthermore, the BALF TP and ALB concentrations in the ARDS + MSC-shLats1 group were lower compared with the ARDS + MSC-shcontrol group (all $\mathrm{P}<0.05$; Fig. 4C-F). Western blot detection of the lung tissue epithelial tight junction protein occludin is used for characterization of permeability of lung epithelium (19). Occludin expression in the lung tissue of the ARDS + MSC-shcontrol group significantly increased compared with the ARDS group 14 days after LPS exposure $(\mathrm{P}<0.05)$. Furthermore, occludin protein expression level in the lung tissue of the ARDS + MSC-shLats1 group increased compared with the ARDS + MSC-shcontrol group 14 days after LPS exposure ( $\mathrm{P}<0.05$; Fig. 4G). These results indicate that mMSCs with downregulated Hippo signaling may improve pulmonary edema and the permeability of lung epithelium in ARDS lung tissue.

mMSCs with downregulated Hippo signaling improve inflammation in ARDS lung tissue. To evaluate the levels of lung inflammation in different groups, concentrations of the proinflammatory factors IL-1 $\beta$ and -6 , and the anti-inflammatory factors IL-4 and -10 in the BALF were measured using ELISA kits. IL- $1 \beta$ and -6 concentrations in the BALF of the ARDS + MSC-shcontrol group were significantly lower compared with the ARDS group $(\mathrm{P}<0.05)$, whereas IL-4 and -10 concentrations were significantly increased compared with the ARDS group $(\mathrm{P}<0.05)$. Furthermore, IL-1 $\beta$ and -6 concentrations in the BALF of the ARDS + MSC-shLats1 group were lower compared with the ARDS + MSC-shcontrol 


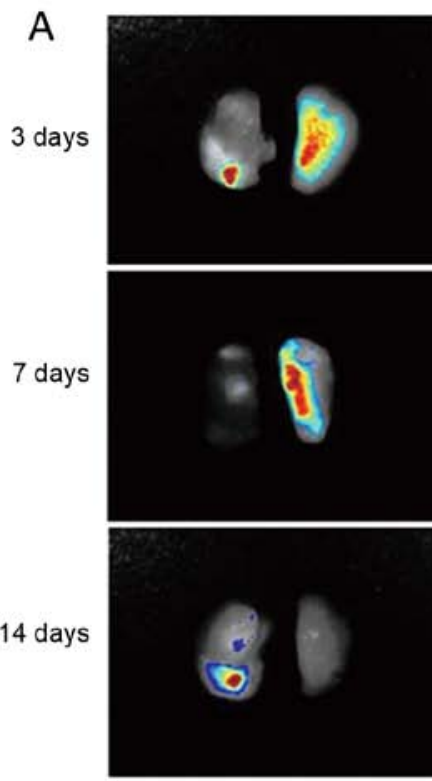

ARDS+MSC-shcontro
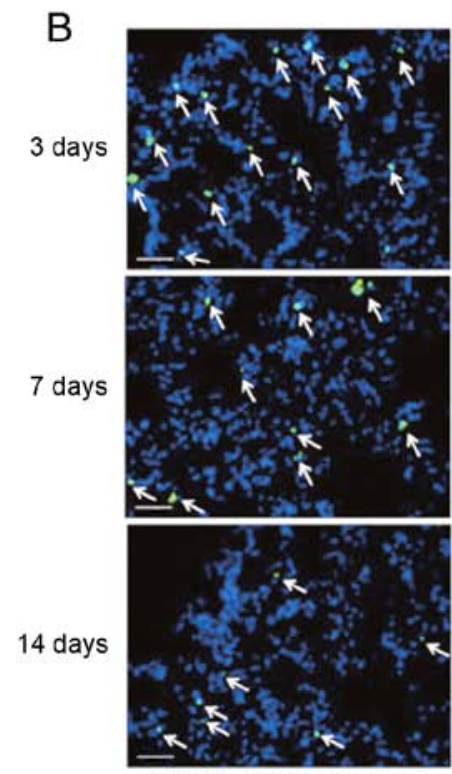

ARDS+MSC-shcontrol
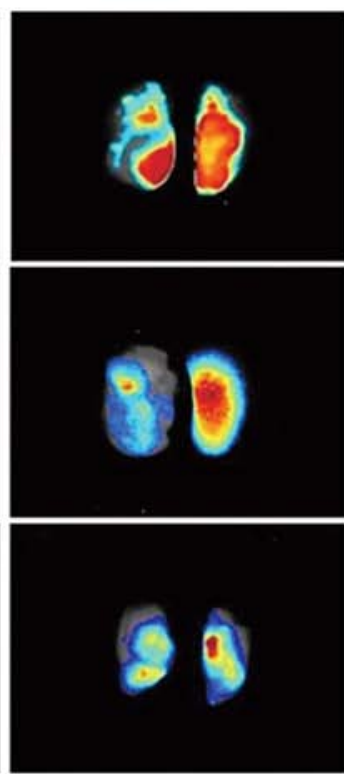

ARDS+MSC-shLats1
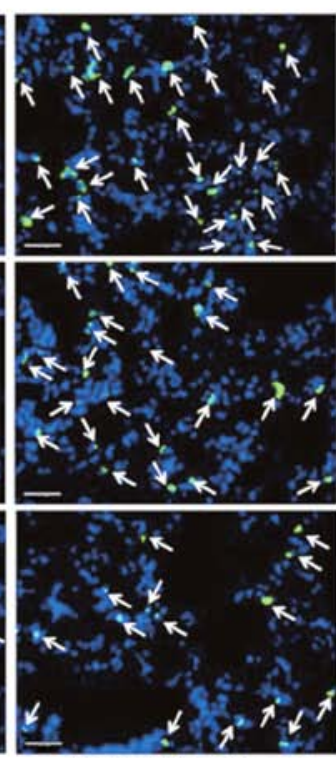

ARDS+MSC-shLats1
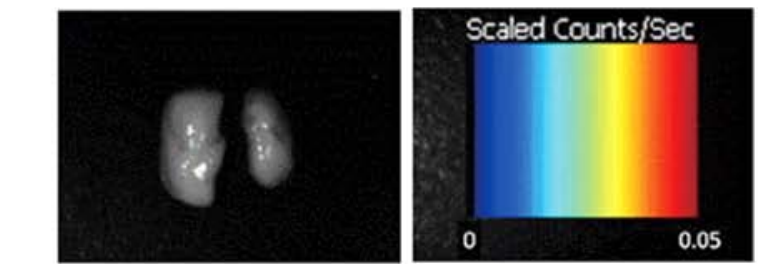

Control
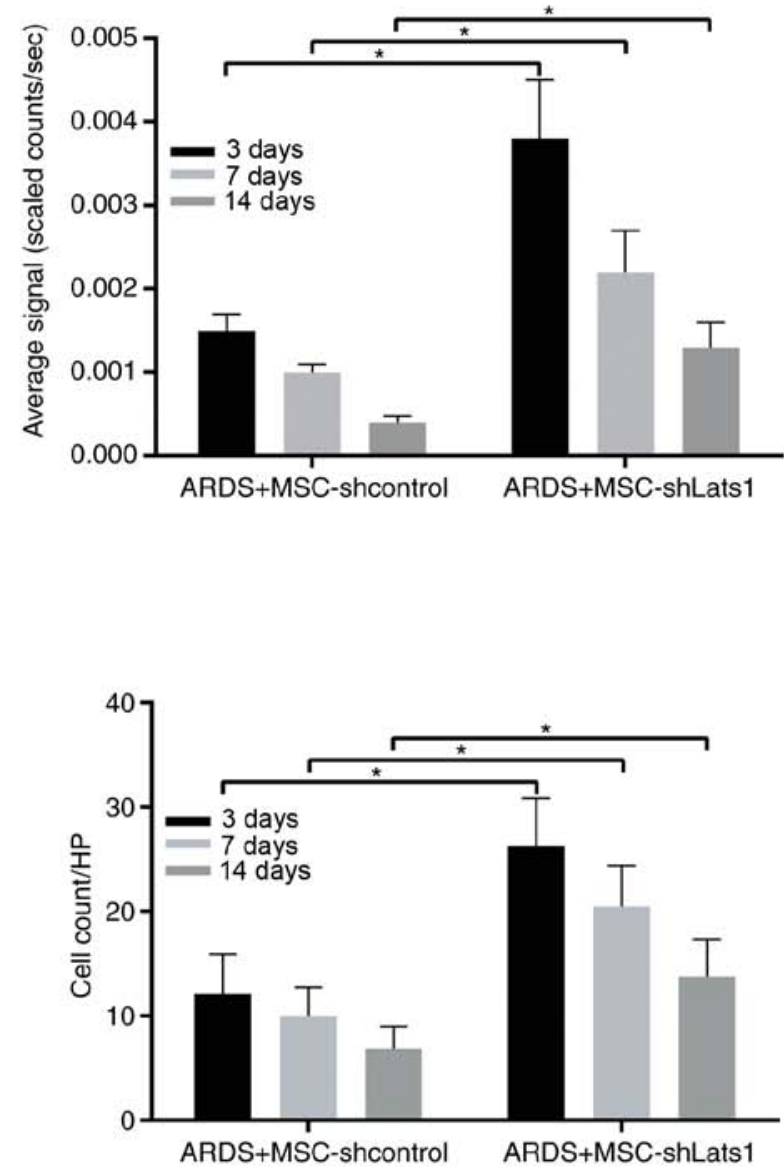

Figure 2. Effect of Lats1 knockdown on mMSCs retention in ARDS lung tissue. (A) Representative near-infrared images of ex vivo lungs in the ARDS + MSC-shLats1 and ARDS + MSC-shcontrol groups are shown from three mouse lungs obtained 3, 7, and 14 days after LPS exposure. (B) Representative immunofluorescence staining of lung tissue in the ARDS + MSC-shLats1 and ARDS + MSC-shcontrol groups are presented from three mouse lungs obtained 3, 7 and 14 days after LPS exposure. The nuclei were stained with DAPI (blue), and the engrafted mMSCs in the lung tissue are shown as GFP-positive (green; magnification, $\mathrm{x} 400$; scale bar, $20 \mu \mathrm{m}$; white arrows, GFP-positive cells). The cell count of GFP-positive mMSCs in randomly selected high-power fields is presented as the mean \pm standard deviation $(\mathrm{n}=6) .{ }^{*} \mathrm{P}<0.05$. mMSC, bone marrow-derived mesenchymal stem cell; Lats1, large tumor suppressor kinase; GFP, green fluorescent protein; sh, short hairpin RNA; HP, high-power field.

group (both $\mathrm{P}<0.05$; Fig. $5 \mathrm{~A}$ and $\mathrm{B}$ ), whereas IL-4 and -10 concentrations were greater in the ARDS + MSC-shLats1 group compared with the ARDS + MSC-shcontrol group (both $\mathrm{P}<0.05$; Fig. 5C and D). These results indicate that mMSCs with downregulated Hippo signaling improved inflammation in ARDS lung tissue by reducing the levels of proinflammatory factors and increasing the level of anti-inflammatory factors.

mMSCs with downregulated Hippo signaling attenuate pathological injuries in ARDS lung tissue. Edema and bleeding were widespread in the alveoli and interstitium of ARDS lung tissue, whereas no such manifestations were observed in the control mice (Fig. 6A). There was diffuse inflammatory cell infiltration, severe alveolar collapse and structural damage in the lungs of ARDS group animals, and their lung injury score was the highest among all groups examined (all $\mathrm{P}<0.05$ ). Pathological changes and lung injury scores were significantly improved in the ARDS + MSC-shcontrol group compared with the ARDS group 3 and 14 days after LPS exposure (both $\mathrm{P}<0.05)$. Furthermore, pathological changes and lung injury scores in the ARDS + MSC-shLats1 group were further improved compared with the ARDS + MSC-shcontrol group 3 and 14 days after LPS exposure (both $\mathrm{P}<0.05$; Fig. 6A-C). These results indicated that $\mathrm{mMSCs}$ with downregulated 

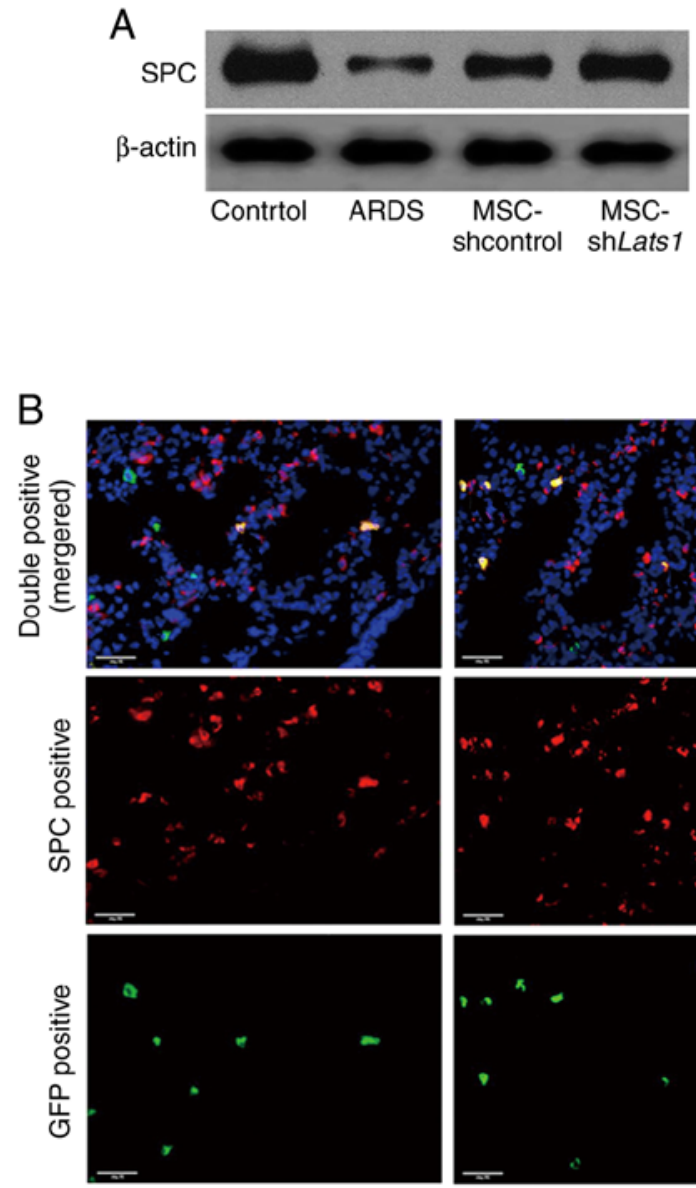

MSC-shcontrol
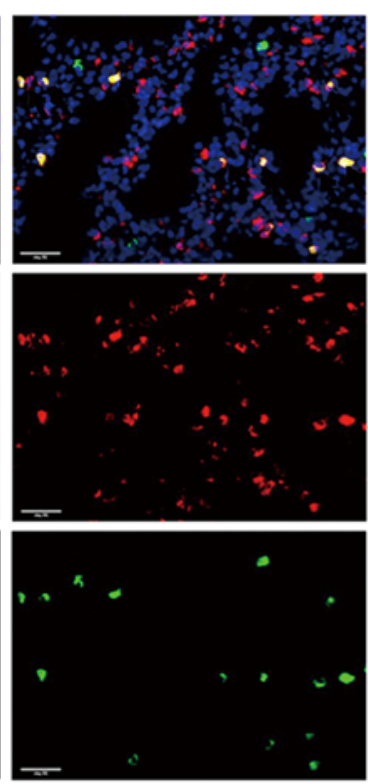

MSC-shLats 1

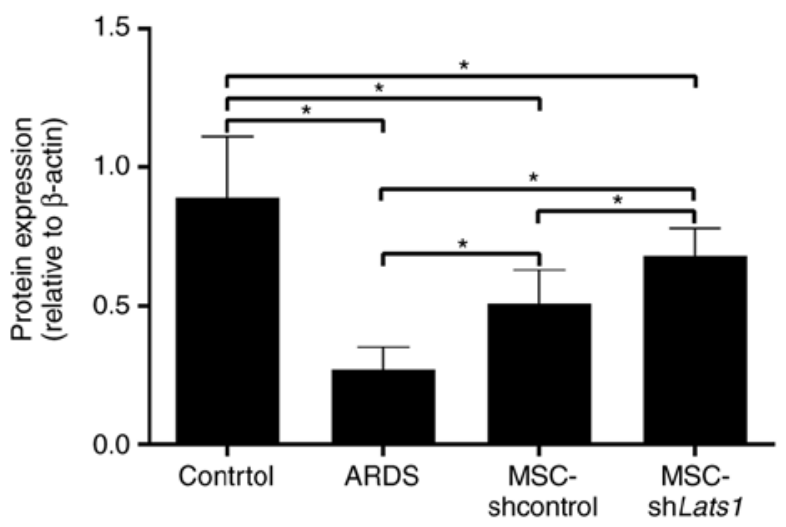

Figure 3. Effect of Lats1 knockdown on the differentiation of mMSCs into ATII cells. (A) The protein expression level of SPC in the lung tissue was measured using western blotting 14 days after mMSC administration. $\beta$-actin was used as an internal reference, and the results are presented as the mean \pm standard deviation $(\mathrm{n}=6)$. (B) Differentiation of mMSCs into ATII cells was detected by immunofluorescence staining in the ARDS + MSC-shLats1 and ARDS + MSC-shcontrol groups 14 days after mMSC administration. Engrafted mMSCs and ATII cells in the lung tissue are shown as GFP-positive (green) or SPC-positive (red) under fluorescence microscopy, respectively, while mMSCs that differentiated into ATII cells are shown as double-positive (yellow). The nuclei were stained with DAPI (blue; magnification, $\mathrm{x} 400$; scale bar, $20 \mu \mathrm{m}$ ). The ratio of the count of double-positive cells to the count of GFP-positive cells in randomly selected high-power fields is presented as the mean \pm standard deviation $(\mathrm{n}=6)$. ${ }^{*} \mathrm{P}<0.05$. mMSCs, bone marrow-derived mesenchymal stem cell; Lats1, large tumor suppressor kinase 1; SPC, surfactant protein C; ATII, alveolar type II epithelial; GFP, green fluorescent protein; ARDS, acute respiratory distress syndrome; sh, short hairpin RNA.

Hippo signaling may ameliorate the pathological injuries in ARDS lung tissue.

mMSCs with downregulated Hippo signaling reduce pulmonary fibrosis in ARDS lung tissue. To assess the degree of pulmonary fibrosis in mice from different experimental groups, modified Masson's staining of lung tissue samples was conducted, and semiquantitative scoring was performed, as previously described by Ashcroft et al (14). This analysis revealed hyperplasia of collagen fiber tissue in alveolar septa and alveolar cavities in samples from the ARDS group at 14 days, with clear thickening of alveolar walls and partial loss of alveolar structure (Fig. 7A). The lung fibrosis score in the ARDS group was significantly increased compared with the control group $(\mathrm{P}<0.05)$. A decreased deposition of focal and filamentous collagen fibers was found in the lung tissue of the ARDS + MSC-shcontrol group, and the lung fibrosis score was significantly lower compared with the ARDS group $(\mathrm{P}<0.05)$. No collagen fiber formation was detected in samples from the ARDS + MSC-shLats1 group, and the lung fibrosis score for these samples was lower compared with the ARDS + MSC-shcontrol group $(\mathrm{P}<0.05$; Fig. 7A and $\mathrm{B})$. These results indicate that $\mathrm{mMSCs}$ with downregulated Hippo signaling may reduce fibrosis in ARDS lung tissue.

\section{Discussion}

The present study investigated the effects of mMSCs on the extent of lung injury and fibrosis in an LPS-induced mouse model of ARDS lung injury. In addition, prompted by our previously reported in vitro data (11), the current study aimed to determine whether the putative beneficial effects of MSC administration in the model of ARDS could be further potentiated by the inhibition of the Hippo signaling pathway in these cells. 

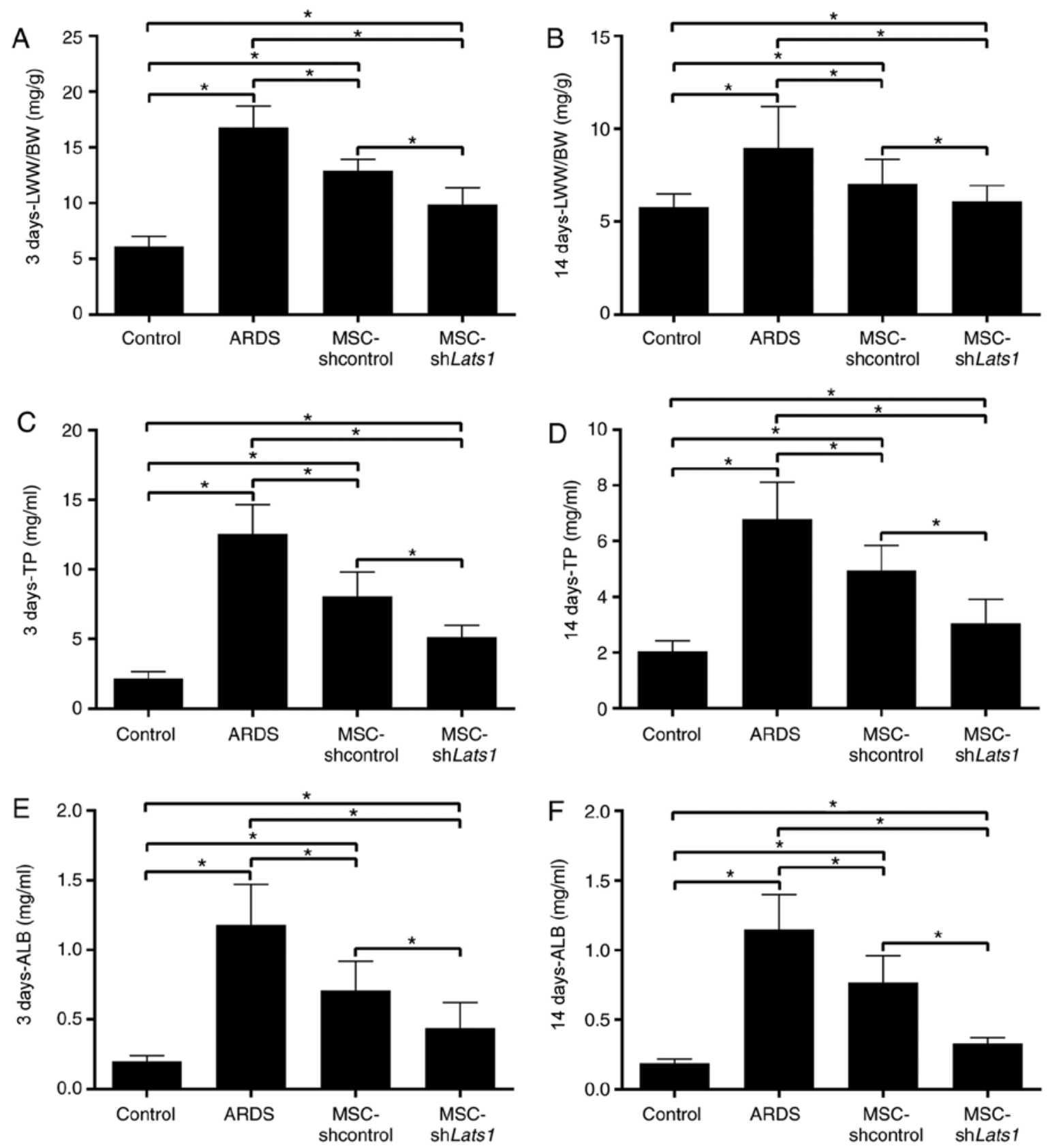

G
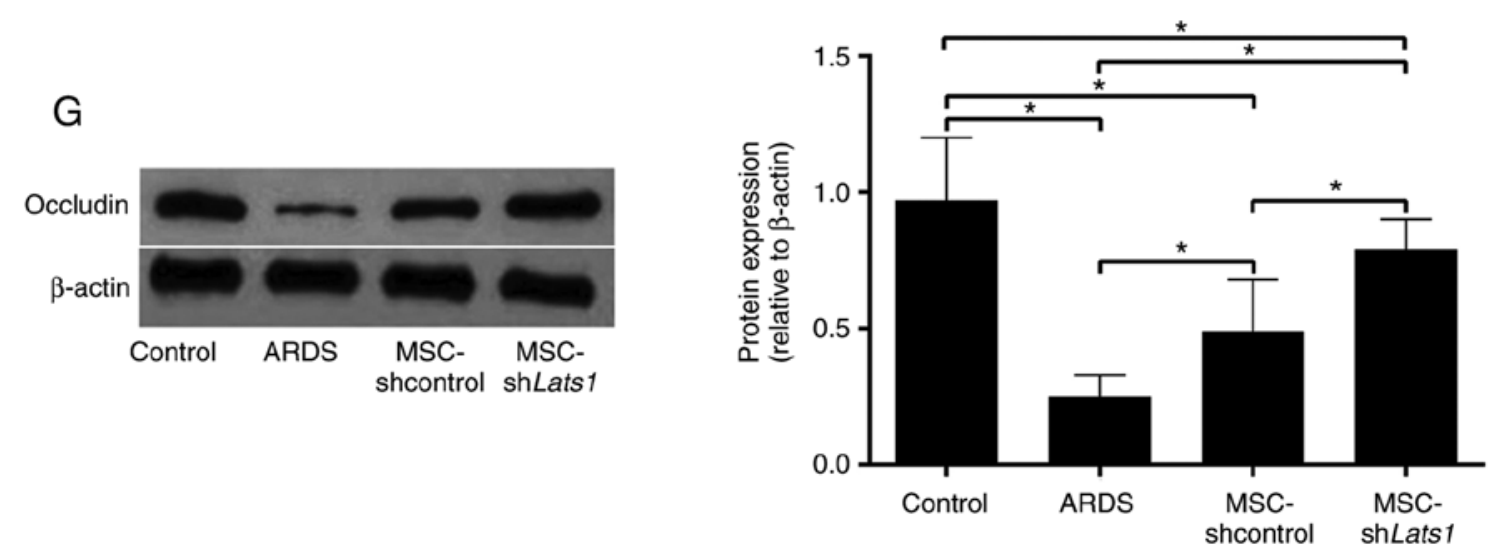

Figure 4. Effect of mMSCs with downregulated Hippo signaling on pulmonary edema and permeability of lung epithelium in ARDS lung tissue. The degree of pulmonary edema was determined by the LWW/BW (A) 3 and (B) 14 days after LPS exposure. TP level in BALF was measured (C) 3 and (D) 14 days after LPS exposure. ALB concentration was measured in BALF (E) 3 and (F) 14 days after LPS exposure. (G) Western blotting was performed 14 days after LPS exposure to determine the expression level of tight junction protein occludin in the lung tissue. $\beta$-actin was used as an internal reference. The results are presented as the mean \pm standard deviation of values obtained from six mice per group at each time point. $\mathrm{P}<0.05$. mMSCs, bone marrow-derived mesenchymal stem cell; ARDS, acute respiratory distress syndrome; LPS, lipopolysaccharide; LWW/BW, lung wet weight/body weight ratio; ALB, albumin; TP, total protein; sh, short hairpin RNA; Lats1, large tumor suppressor kinase; BALF, bronchoalveolar lavage fluid. 

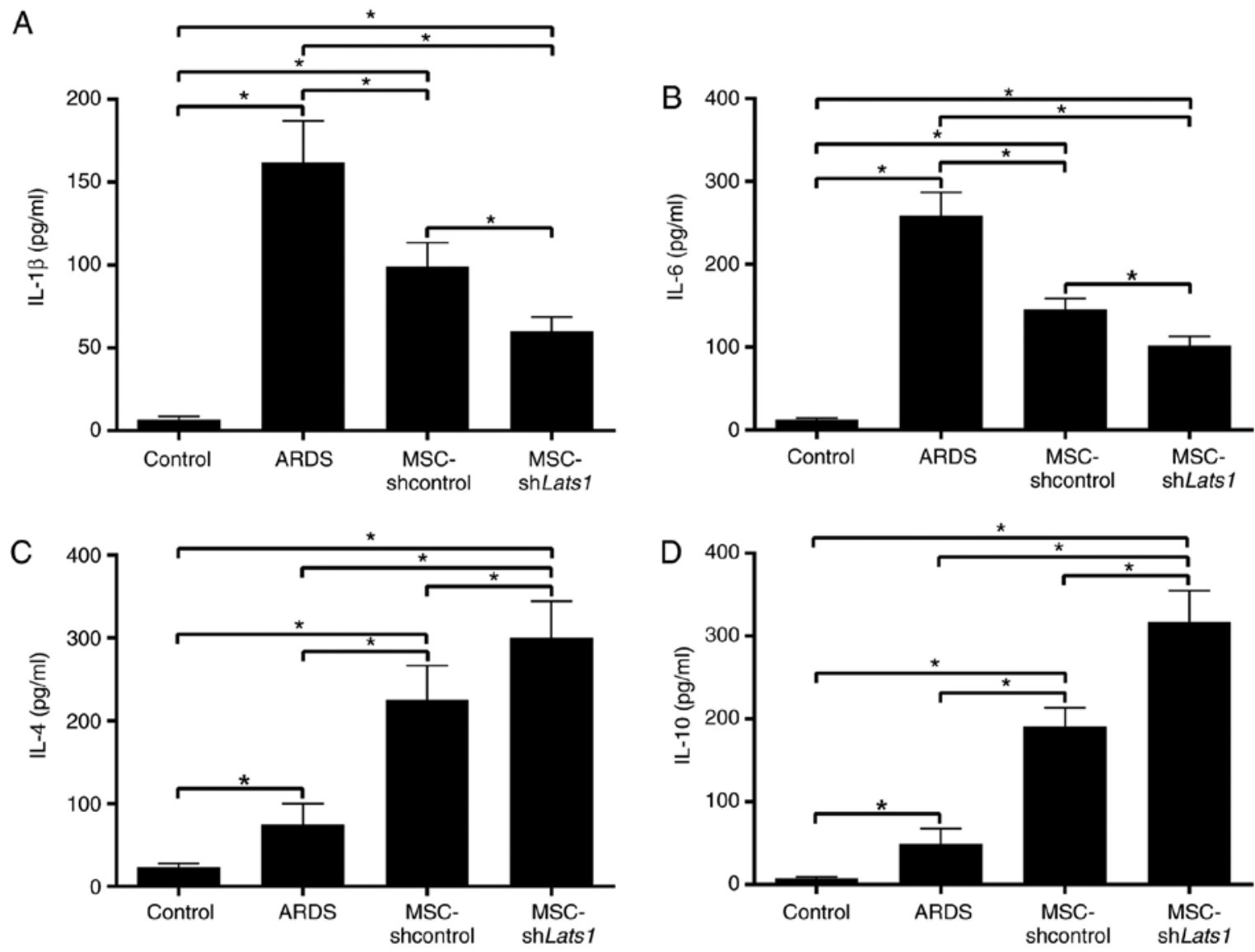

Figure 5. Effect of mMSCs with downregulated Hippo signaling on inflammation in ARDS lung tissue. The levels of the proinflammatory cytokines (A) IL-1 $\beta$ and (B) IL-6, and anti-inflammatory cytokines (C) IL-4 and (D) IL-10 in bronchoalveolar lavage fluid were measured using ELISA kits 3 days after lipopolysaccharide exposure. Data are presented as the mean \pm standard deviation $(n=6) .{ }^{*} \mathrm{P}<0.05$. mMSCs, bone marrow-derived mesenchymal stem cell; ARDS, acute respiratory distress syndrome; IL, interleukin; sh, short hairpin RNA; Lats1, large tumor suppressor kinase.

Alveolar epithelial injury is the main pathophysiological basis of ARDS (1). ATII cells that remain after the injury can proliferate and differentiate into ATI epithelial cells to repair lung damage (4). However, ATII cells are severely damaged in moderate and severe ARDS, and the quantity of cells may be insufficient to repair damaged alveolar epithelium, and supplementation with exogenous cells for repair is a feasible option (20). mMSCs originate from multipotent stem cells of the mesoderm, and previous studies have revealed that exogenous mMSCs delivered to animals with ARDS alleviated the injured alveolar epithelium and reduced the mortality rate $(5,6)$. However, the inability of mMSCs to target the lung, short retention time in the lung and low differentiation efficiency are issues that remain encountered in cell-based ARDS treatments $(21,22)$. Previously, in vitro experiments revealed that low expression of the signaling molecule Lats1 inhibits the activation of the Hippo signaling pathway and enhances MSC proliferation, differentiation into ATII cells and homing to ARDS-affected lung tissue (23). Manipulating Hippo signaling activity may be an important strategy to maximize the protective effect of mMSCs in the lungs, and the present study validated this concept through in vivo experiments.

The Hippo signaling pathway is an essential biochemical cascade for the regulation of cell proliferation and differentiation in numerous types of tissues (24). Hippo signaling begins with the binding of the cell surface ligand dachsous homolog 1 and 2 to the cell surface receptor FAT tumor suppressor homolog 4 on a neighboring cell, which activates the serine/threonine-protein kinase STE20 family mammalian sterile 20-like kinases 1 and 2, thereby phosphorylating and activating the nuclear dbf2-related family kinase Lats1 (25). Lats1 kinase phosphorylates the downstream transcriptional regulator Yes-associated protein (YAP), inhibiting proliferative and antiapoptotic activities of the Hippo signaling pathway, thus promoting apoptosis. When Lats1 activity decreases, YAP remains unphosphorylated, which stimulates proliferative and antiapoptotic activities of the Hippo signaling pathway, thus promoting cell proliferation (26). Numerous ligands, receptors, kinases, transcriptional regulators and transcription factors of the Hippo signaling pathway are expressed in mMSCs; therefore, regulating the activity of this pathway may affect the differentiation, proliferation, migration and other biological functions of mMSCs (27).

In the current study, a mMSCs cell line with Lats1 expression knockdown was successfully established through cell transfection with a lentiviral vector carrying the Lats1 shRNA sequence, thereby inhibiting the Hippo signaling activity in mMSCs. Ex vivo experiments have confirmed that this manipulation promoted MSC differentiation, proliferation and migration (11). In the present study, mMSCs with knockdown of Lats1 were transplanted into ARDS mice via the airway, and then, these mMSCs were evaluated for their retention in 

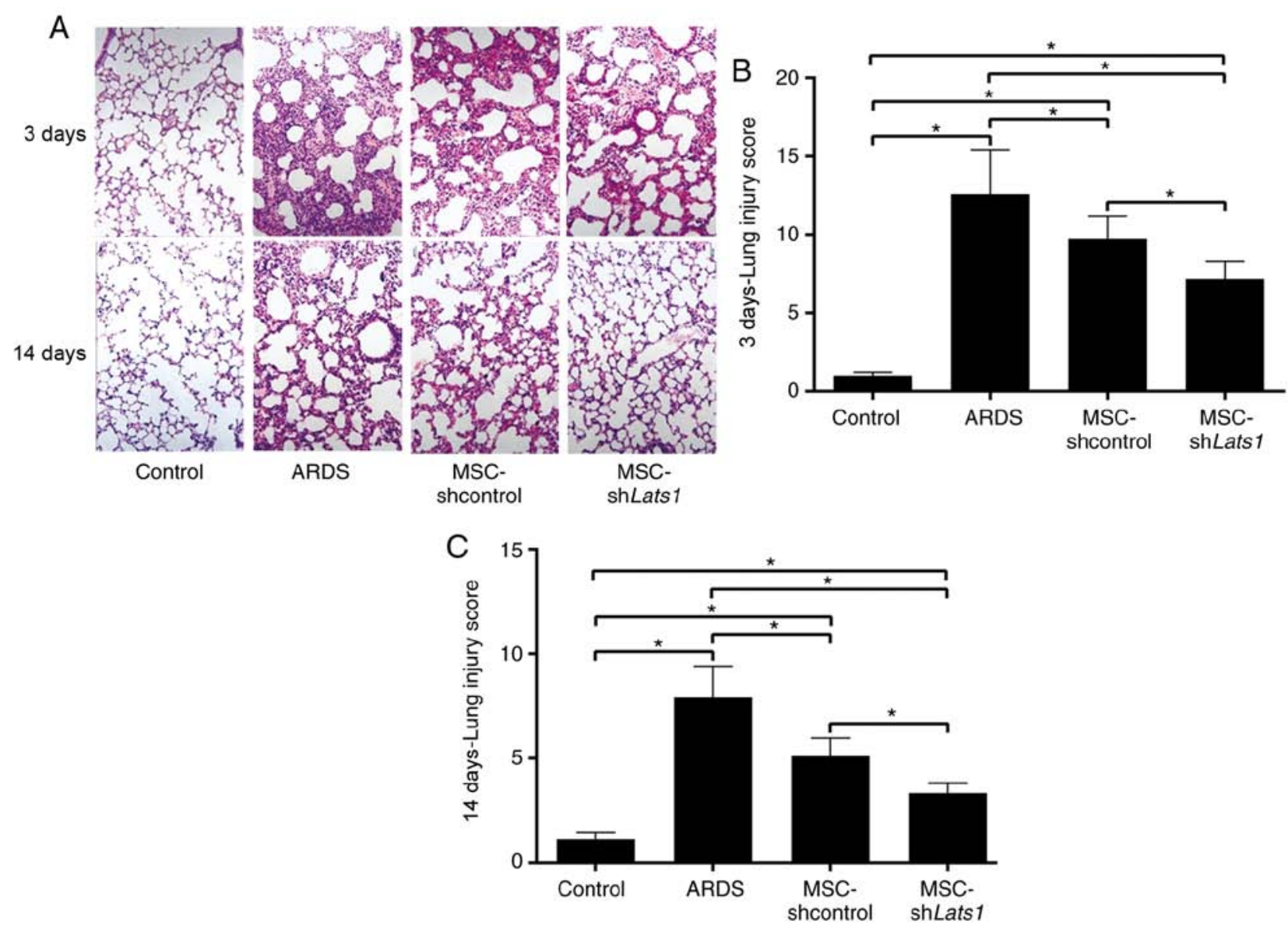

Figure 6. Effect of mMSCs with downregulated Hippo signaling on the pathological changes of ARDS lung tissue. Histopathological analysis of lung tissues was performed 3 and 14 days after LPS exposure. (A) Hematoxylin and eosin staining (magnification, x400) 3 and 14 days after LPS exposure. (B) Lung injury scores 3 days after LPS exposure. (C) Lung injury scores 14 days after LPS exposure. Lung injury scores are expressed using arbitrary units. Data are presented as the mean \pm standard deviation $(n=6) .{ }^{*} \mathrm{P}<0.05$. mMSCs, bone marrow-derived mesenchymal stem cell; ARDS, acute respiratory distress syndrome; LPS, lipopolysaccharide; sh, short hairpin RNA; Lats1, large tumor suppressor kinase.

A

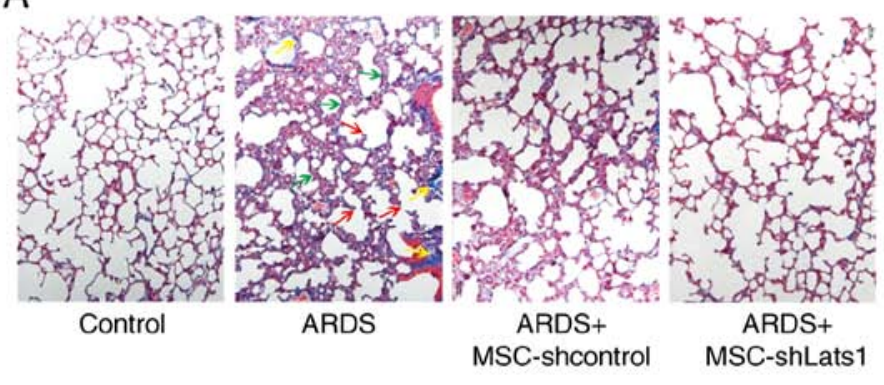

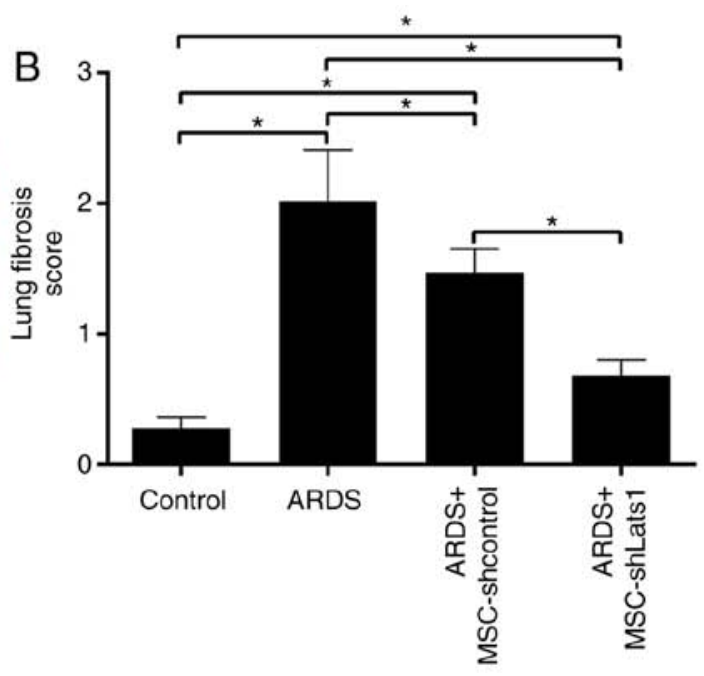

Figure 7. Effect of mMSCs with downregulated Hippo signaling on fibrosis in ARDS lung tissue. Fibrosis of lung tissues was evaluated 14 days after LPS exposure. (A) Modified Masson's staining (magnification, $\mathrm{x} 400$; yellow arrows, collagen fiber formation; green arrows, thickening of alveolar walls; red arrows, partial loss of alveolar structure). (B) Lung fibrosis scores 14 days after LPS exposure. Lung fibrosis scores are expressed using arbitrary units. Data are presented as the mean \pm standard deviation $(\mathrm{n}=6)$. ${ }^{*} \mathrm{P}<0.05$. mMSCs, bone marrow-derived mesenchymal stem cell; ARDS, acute respiratory distress syndrome; sh, short hairpin RNA; Lats1, large tumor suppressor kinase; LPS, lipopolysaccharide.

ARDS lung tissue, differentiation into ATII cells and capacity for repairing lung injury.
We found that Lats1 knockdown increased the retention of mMSCs in ARDS lung tissue. Following administration of 
cells to mice, the retention of exogenous mMSCs in ARDS lung tissue provided evidence of their capacity for tissue repair. $\mathrm{Xu}$ et al (28) confirmed that significantly greater amounts of transplanted MSCs were capable of homing to ARDS lung tissue compared with the normal lung tissue. Currently, the molecular mechanisms that regulate MSC migration toward sites of injury remain unknown. A previous study indicated that transforming growth factor- $\beta 1$, IL- $1 \beta$ and tumor necrosis factor (TNF)- $\alpha$ enhance MSCs homing by inducing the expression of matrix metalloproteases (29). Furthermore, it has been reported that stem cell-derived factor- $1 \alpha$ and C-X-C chemokine receptor type 4 may participate in MSCs homing (30). The present study confirmed that the Hippo signaling pathway regulates mMSCs retention in the ARDS lung tissue in vivo, providing a new perspective for the molecular mechanism of MSC migration and homing. However, the in vivo efficacy and mechanisms of this regulation require further investigation.

Lats1 knockdown increased the differentiation of mMSCs into ATII cells. This result contrasts with data reported in several previous studies. In a study by An et al (31) the Hippo signaling pathway positively affected adipogenesis. Furthermore, Tang et al (32) demonstrated that activation of the Hippo signaling pathway in mMSCs cultured in a myogenic environment promoted their differentiation into muscle fiber cells. However, Chen et al (33) revealed that activation of the Hippo signaling pathway in mMSCs cultured in an osteogenic environment inhibited their differentiation into osteocytes. In addition, $\mathrm{He}$ et al (34) revealed a negative regulatory role of the Hippo signaling pathway in adipogenesis. Knockdown of YAP in mMSCs cultured in an adipogenic environment increased the formation of adipocytes (34). From these studies, it is evident that the regulatory roles of the Hippo signaling pathway on mMSCs differ and likely depend on the cell type, environment, duration and time of treatment (35).

Cell permeability in pulmonary edema resulting from the damage to tight junction proteins of alveolar epithelial cells is one of the important factors underlying decreased lung compliance and intractable hypoxia in ARDS (36). In the present study, mMSCs with downregulated Hippo signaling differentiated into alveolar epithelial cells and reinforced alveolar epithelial tight junctions. This may be a potential mechanism by which mMSCs with downregulated Hippo signaling can improve pulmonary edema and permeability in ARDS lung tissue. Previous studies have also yielded similar results; for example, Pati et al (37) found that the administration of exogenous MSCs in hemorrhagic shock-associated lung injury improved endothelial permeability and diminished pulmonary edema through the protection of endothelial tight junctions of pulmonary blood vessels. In the present study, the inhibition of the Hippo signaling pathway further enhanced the protective role of mMSCs on the alveolar epithelial barrier.

Dysregulation of inflammatory reactions in the lung is one of the main pathological mechanisms of ARDS, which is primarily manifested as local proinflammatory reactions in the lung tissue and reduced anti-inflammatory activity (38). In the present study, mMSCs with downregulated Hippo signaling reduced the levels of the proinflammatory factors IL- $1 \beta$ and -6 and increased the levels of the anti-inflammatory factors IL-4 and -10 in the lung tissue, thereby ameliorating the imbalance in proinflammatory/anti-inflammatory reactions in the lungs. These observations are similar to the results reported by Zhu et al (39), who revealed that the administration of exogenous MSCs reduced IL-6 secretion and augmented IL-10 secretion in the lung tissue of a mouse model of ARDS. The current study revealed that the inhibition of the Hippo signaling pathway further reinforced the positive regulatory impact of mMSCs on lung inflammation in ARDS. In addition, the stimulation of other type 2 anti-inflammatory cytokines, including IL-13, and the inhibition of proinflammatory cytokines, such as TNF- $\alpha$, should be further investigated $(40,41)$.

The extent of the pathological alterations in the lung tissue is the key parameter for ARDS diagnosis, treatment efficacy and determination of prognosis (42). Bleeding, edema, collapse and inflammatory cell infiltration in the alveoli are typical pathological alterations associated with ARDS (43). Pulmonary fibrosis resulting from increased collagen fiber production during the lung injury repair process may directly affect pulmonary function and the long-term quality of life of patients with ARDS (44). In addition, a previous study revealed that pathological changes associated with pulmonary fibrosis begin to appear $24 \mathrm{~h}$ after the development of ARDS (45). In the present study, mMSCs with downregulated Hippo signaling improved pathological injuries and reduced fibrosis in ARDS lung tissue in mice. In addition, the inhibition of multiple fibrotic pathways may be involved in the antifibrotic effects of MSC-shLats1, which warrants further studies (46). Therefore, similar approaches may potentially reduce the mortality rate of ARDS and improve the long-term prognosis in human patients. These results are similar to those reported in several previous studies. Devaney et al (47) revealed that the administration of MSCs into the airway improved pathological injuries in a rat model of ARDS. Furthermore, Shen et al (48) reported that the intratracheal administration of MSCs significantly reduced collagen fiber formation in a mouse model of ARDS. In addition, in the current study, the inhibition of the Hippo signaling pathway in administered mMSCs further increased the efficacy of the treatment of pathological injuries and pulmonary fibrosis in ARDS. Further studies may be required to investigate the potential use of MSC-shLats1 for the treatment of other forms of fibrosis, including liver fibrosis (49).

The present study had certain limitations. First, ARDS is a clinical disorder with marked heterogeneity in its etiology and pathophysiology, and LPS-induced ARDS only represents a direct insult on lung cells (50). Second, the present study did not investigate the effect of mMSCs with downregulated Hippo signaling on the LPS-Toll-like receptor 4 signaling pathway, which initiates inflammation and injury in LPS-induced ARDS (51), and, therefore, further studies are warranted.

In conclusion, the current study demonstrated that the transplantation of mMSCs with Lats1 gene knockdown to inhibit the Hippo signaling pathway in mice with LPS-induced ARDS promoted mMSCs retention in ARDS lung tissue and their differentiation into ATII cells. The use of these modified mMSCs improved pulmonary edema, reduced inflammatory reactions, and attenuated pathological injuries and fibrotic changes in the lung tissue of animals with ARDS. The results of the current study indicate that regulation of the Hippo signaling pathway may enhance the repair efficacy of mMSCs in ARDS, however, clinical trials are required. 


\section{Acknowledgments}

The authors thank Dr Qiuhui Wang (Wuxi People's Hospital, Wuxi, China) for assistance with modified Masson's staining and immunofluorescence staining of lung tissues.

\section{Funding}

The present study was supported by the National Natural Science Foundation of China (grant no. 81400054), the Natural Science Foundation of Jiangsu Province (grant no. BK20140122), the Talented Youth Program of Jiangsu Province (grant no. QNRC2017179) and the Fifth '333 High Level Talent Training Project' of Jiangsu Province (grant no. 2018III-0299).

\section{Availability of data and materials}

All data generated or analyzed during this study are included in this article.

\section{Authors' contributions}

LL and LD conceived and designed the study. LL, LD, JZ, FG, $\mathrm{JH}$ and JY performed the experiments, analyzed the data, and interpreted the results. LD, JH and JY generated the figures and drafted the manuscript. All authors have read and revised the manuscript.

\section{Ethics approval and consent to participate}

The experimental protocols were approved by the Institutional Animal Care and Use Committee at Nanjing Medical University (approval no. LLSP201505033). All animal experiments were conducted in accordance with the National Institutes of Health Guide for the Care and Use of Laboratory Animals.

\section{Patient consent for publication}

Not applicable.

\section{Competing interests}

The authors declare that they have no competing interests.

\section{References}

1. Thompson BT, Chambers RC and Liu KD: Acute respiratory distress syndrome. N Engl J Med 377: 562-572, 2017.

2. Fan E, Brodie D and Slutsky AS: Acute respiratory distress syndrome: Advances in diagnosis and treatment. JAMA 319: 698-710, 2018.

3. Lau AN, Goodwin M, Kim CF and Weiss DJ: Stem cells and regenerative medicine in lung biology and diseases. Mol Ther 20: 1116-1130, 2012.

4. Weiss DJ: Stem cells, cell therapies, and bioengineering in lung biology and diseases. Comprehensive review of the recent literature 2010-2012. Ann Am Thorac Soc 10: S45-S97, 2013.

5. Lee JW, Gupta N, Serikov V and Matthay MA: Potential application of mesenchymal stem cells in acute lung injury. Expert Opin Biol Ther 9: 1259-1270, 2009.

6. Xu F, Hu Y, Zhou J and Wang X: Mesenchymal stem cells in acute lung injury: Are they ready for translational medicine? J Cell Mol Med 17: 927-935, 2013.
7. Bustos ML, Huleihel L, Kapetanaki MG, Lino-Cardenas CL, Mroz L, Ellis BM, McVerry BJ, Richards TJ, Kaminski N, Cerdenes $\mathrm{N}$, et al: Aging mesenchymal stem cells fail to protect because of impaired migration and antiinflammatory response. Am J Respir Crit Care Med 189: 787-798, 2014.

8. Laffey JG and Matthay MA: Fifty years of research in ARDS. Cell-based therapy for acute respiratory distress syndrome. Biology and potential therapeutic value. Am J Respir Crit Care Med 196: 266-273, 2017.

9. Yang SR, Park JR and Kang KS: Reactive oxygen species in mesenchymal stem cell aging: Implication to lung diseases. Oxid Med Cell Longev 2015: 486263, 2015.

10. Espinoza F, Aliaga F and Crawford PL: Overview and perspectives of mesenchymal stem cell therapy in intensive care medicine. Rev Med Chil 144: 222-231, 2016 (In Spanish).

11. Li L, Dong L, Hui J, Gao F, Wang Q, Yang L, Zhang J and Yan J: Under-expression of LATS1 promotes the differentiation, proliferation and migration of mesenchymal stem cells by inhibition the Hippo signaling pathway in vitro. Zhonghua Wei Zhong Bing Ji Jiu Yi Xue 29: 731-737, 2017 (In Chinese).

12. National Research Council (US) Institute for Laboratory Animal Research: Guide for the Care and Use of Laboratory Animals. National Academies Press, Washington, DC, 1996.

13. Smith KM, Mrozek JD, Simonton SC, Bing DR, Meyers PA, Connett JE and Mammel MC: Prolonged partial liquid ventilation using conventional and high-frequency ventilatory techniques: Gas exchange and lung pathology in an animal model of respiratory distress syndrome. Crit Care Med 25: 1888-1897, 1997.

14. Ashcroft T, Simpson JM and Timbrell V: Simple method of estimating severity of pulmonary fibrosis on a numerical scale. J Clin Pathol 41: 467-470, 1988.

15. He H, Liu L, Chen Q, Liu A, Cai S, Yang Y, Lu X and Qiu H: Mesenchymal stem cells overexpressing angiotensin-converting enzyme 2 rescue lipopolysaccharide-induced lung injury. Cell Transplant 24: 1699-1715, 2015.

16. Livak KJ and Schmittgen TD: Analysis of relative gene expression data using real-time quantitative PCR and the 2(-Delta Delta C(T)) method. Methods 25: 402-408, 2001.

17. Dong L, He HL, Lu XM, Yang Y and Qiu HB: Modulation of FLT3 signaling targets conventional dendritic cells to attenuate acute lung injury. APMIS 120: 808-818, 2012.

18. Sun Y, Liu JG, Zheng YC, Xiao CL, Wan B, Guo L, Wang XG and Bo W: Research on rat's pulmonary acute injury induced by lunar soil simulant. J Chin Med Assoc 81: 133-140, 2018.

19. Tam A, Wadsworth S, Dorscheid D, Man SF and Sin DD: The airway epithelium: More than just a structural barrier. Ther Adv Respir Dis 5: 255-273, 2011.

20. Standiford TJ and Ward PA: Therapeutic targeting of acute lung injury and acute respiratory distress syndrome. Transl Res 167: 183-191, 2016.

21. Moodley Y, Sturm M, Shaw K, Shimbori C, Tan DB, Kolb M and Graham R: Human mesenchymal stem cells attenuate early damage in a ventilated pig model of acute lung injury. Stem Cell Res 17: 25-31, 2016.

22. McIntyre LA, Moher D, Fergusson DA, Sullivan KJ, Mei SH, Lalu M, Marshall J, Mcleod M, Griffin G, Grimshaw J, et al: Efficacy of mesenchymal stromal cell therapy for acute lung injury in preclinical animal models: A systematic review. PLoS One 11: e0147170, 2016.

23. Hayes M, Curley G, Ansari B and Laffey JG: Clinical review: Stem cell therapies for acute lung injury/acute respiratory distress syndrome-hope or hype? Crit Care 16: 205, 2012.

24. Sardo FL, Strano S and Blandino G: The Hippo kinase pathway: A master regulator of proliferation, development and differentiation. Atlas Genet Cytogenet Oncol Haematol 19: 65-77, 2015.

25. Johnson R and Halder G: The two faces of Hippo: Targeting the Hippo pathway for regenerative medicine and cancer treatment. Nat Rev Drug Discov 13: 63-79, 2014.

26. Zhang Q, Meng F, Chen S, Plouffe SW, Wu S, Liu S, Li X, Zhou R, Wang J,Zhao B, et al: Hippo signalling governs cytosolic nucleic acid sensing through YAP/TAZ-mediated TBK1 blockade. Nat Cell Biol 19: 362-374, 2017.

27. Zhao B, Tumaneng K and Guan KL: The Hippo pathway in organ size control, tissue regeneration and stem cell self-renewal. Nat Cell Biol 13: 877-883, 2011.

28. Xu J, Woods CR, Mora AL, Joodi R, Brigham KL, Iyer S and Rojas M: Prevention of endotoxin-induced systemic response by bone marrow-derived mesenchymal stem cells in mice. Am J Physiol Lung Cell Mol Physiol 293: L131-L141, 2007. 
29. De Becker A, Van Hummelen P, Bakkus M, Vande Broek I, De Wever J, De Waele Mand Van Riet I: Migration of culture-expanded human mesenchymal stem cells through bone marrow endothelium is regulated by matrix metalloproteinase- 2 and tissue inhibitor of metalloproteinase-3. Haematologica 92: 440-449, 2007.

30. Schioppa T, Uranchimeg B, Saccani A, Biswas SK, Doni A, Rapisarda A, Bernasconi S, Saccani S, Nebuloni M, Vago L, et al: Regulation of the chemokine receptor CXCR4 by hypoxia. J Exp Med 198: 1391-1402, 2003.

31. An Y, Kang Q, Zhao Y, Hu X and Li N: Lats2 modulates adipocyte proliferation and differentiation via hippo signalling. PLoS One 8: e72042, 2013.

32. Tang Y, Feinberg T, Keller ET, Li XY and Weiss SJ: Snail/Slug binding interactions with YAP/TAZ control skeletal stem cell self-renewal and differentiation. Nat Cell Biol 18: 917-929, 2016.

33. Chen Z, Luo Q, Lin C, Kuang D and Song G: Simulated microgravity inhibits osteogenic differentiation of mesenchymal stem cells via depolymerizing F-actin to impede TAZ nuclear translocation. Sci Rep 6: 30322, 2016.

34. He Q, Huang HY, Zhang YY, Li X, Qian SW and Tang QQ Tang: TAZ is downregulated by dexamethasone during the differentiation of 3T3-L1 preadipocytes. Biochem Biophys Res Commun 419: 573-577, 2012.

35. Deel MD, Li JJ, Crose LE and Linardic CM: A Review: Molecular aberrations within Hippo signaling in bone and soft-tissue sarcomas. Front Oncol 5: 190, 2015.

36. Lin X, Barravecchia M, Kothari P, Young JL and Dean DA: $\beta 1-\mathrm{Na}(+), \mathrm{K}(+)$-ATPase gene therapy upregulates tight junctions to rescue lipopolysaccharide-induced acute lung injury. Gene Ther 23: 489-499, 2016.

37. Pati S, Gerber MH, Menge TD, Wataha KA, Zhao Y, Baumgartner JA, Zhao J, Letourneau PA, Huby MP, Baer LA, et al: Bone marrow derived mesenchymal stem cells inhibit inflammation and preserve vascular endothelial integrity in the lungs after hemorrhagic shock. PLoS One 6: e25171, 2011.

38. Voiriot G, Razazi K, Amsellem V, Tran Van Nhieu J, Abid S, Adnot S, Mekontso Dessap A and Maitre B: Interleukin-6 displays lung anti-inflammatory properties and exerts protective hemodynamic effects in a double-hit murine acute lung injury. Respir Res 18: 64, 2017.

39. Zhu H, Xiong Y, Xia Y, Zhang R, Tian D, Wang T, Dai J, Wang L, Yao $\mathrm{H}$, Jiang $\mathrm{H}$, et al: Therapeutic effects of human umbilical cord-derived mesenchymal stem cells in acute lung injury mice. Sci Rep 7: 39889, 2017.

40. Nicoletti F, Mancuso G, Cusumano V, Di Marco R, Zaccone P, Bendtzen K and Teti G: Prevention of endotoxin-induced lethality in neonatal mice by interleukin-13. Eur J Immunol 27: $1580-1583,1997$.

41. Qi D, Wang D, Zhang C, Tang X, He J, Zhao Y, Deng W and Deng X: Vaspin protects against LPSinduced ARDS by inhibiting inflammation, apoptosis and reactive oxygen species generation in pulmonary endothelial cells via the Akt/GSK3 $\beta$ pathway. Int J Mol Med 40: 1803-1817, 2017.
42. Kao KC, Hu HC, Chang CH, Hung CY, Chiu LC, Li SH, Lin SW, Chuang LP, Wang CW, Li LF, et al: Diffuse alveolar damage associated mortality in selected acute respiratory distress syndrome patients with open lung biopsy. Crit Care 19: 228, 2015.

43. Blondonnet R, Constantin JM, Sapin V and Jabaudon M: A pathophysiologic approach to biomarkers in acute respiratory distress syndrome. Dis Markers 2016: 3501373, 2016.

44. Wilcox ME and Herridge MS: Lung function and quality of life in survivors of the acute respiratory distress syndrome (ARDS). Presse Med 40: e595-603, 2011.

45. Huang K, Wu XM, Wang XY, Kang XW, Xiao JL, Li ZG and Lu P: The effect of marrow mesenchymal stem cell transplantation on pulmonary fibrosis in rats. Zhonghua Jie $\mathrm{He} \mathrm{He} \mathrm{Hu} \mathrm{Xi}$ Za Zhi 35: 659-664, 2012 (In Chinese).

46. Fagone P, Mangano K, Mammana S, Pesce A, Pesce A, Caltabiano R, Giorlandino A,Portale TR, CavalliE,Lombardo GA, et al: Identification of novel targets for the diagnosis and treatment of liver fibrosis. Int J Mol Med 36: 747-752, 2015.

47. Devaney J, Horie S, Masterson C, Elliman S, Barry F, O'Brien T, Curley GF, O'Toole D and Laffey JG: Human mesenchymal stromal cells decrease the severity of acute lung injury induced by E. coli in the rat. Thorax 70: 625-635, 2015.

48. Shen Q, Chen B, Xiao Z, Zhao L, Xu X, Wan X, Jin M, Dai J and Dai H: Paracrine factors from mesenchymal stem cells attenuate epithelial injury and lung fibrosis. Mol Med Rep 11: 2831-2837, 2015.

49. Fagone P, Mangano K, Pesce A, Portale TR, Puleo S and Nicoletti F: Emerging therapeutic targets for the treatment of hepatic fibrosis. Drug Discov Today 21: 369-375, 2016.

50. Shaver CM and Bastarache JA: Clinical and biological heterogeneity in acute respiratory distress syndrome: Direct versus indirect lung injury. Clin Chest Med 35: 639-653, 2014.

51. Liu L, Chen L, Jiang C, Guo J, Xie Y, Kang L and Cheng Z: Berberine inhibits the LPS-induced proliferation and inflammatory response of stromal cells of adenomyosis tissues mediated by the LPS/TLR4 signaling pathway. Exp Ther Med 14: 6125-6130,2017.

This work is licensed under a Creative Commons Attribution-NonCommercial-NoDerivatives 4.0 International (CC BY-NC-ND 4.0) License. 